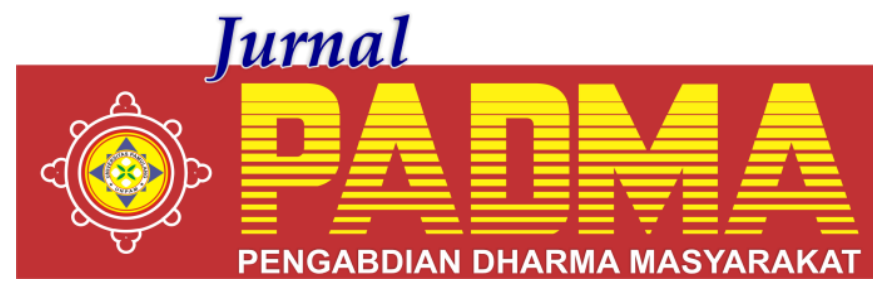

VOLUME 1, NOMOR 4, OKTOBER 2021

\title{
PELATIHAN STRATEGI MARKETING DIMASA PANDEMI USAHA KECIL DAN MENENGAH “USAHA KRUPUK SUPER IKAN LAUT MANDIRI” CISADAP CIAMIS, JAWA BARAT
}

\author{
${ }^{1 *}$ Eka Kusuma Dewi, ${ }^{2}$ Muliyani, ${ }^{3}$ Yunita Kwartarani, ${ }^{4}$ Purwatiningsih, ${ }^{5}$ Dinar Ambarita \\ Universitas Pamulang, Tangerang Selatan, Banten, Indonesia \\ *eka.kusuma.dewi@gmail.com
}

\begin{abstract}
Abstrak
Kami melaksanakan kegiatan Pengabdian dengan 3 tahapan, yaitu penyuluhan perkembangan penjualan e-commerce dan pentingnya pembagian tugas, diskusi mengenai kendala yang dihadapi dan pendampingan pembuatan media penjualan online serta penyusunan struktur organisasi. Setelah mengikuti pelatihan, Usaha kerupuk Super Ikan Laut Mandiri mengalami kemajuan cukup pesat penjualan nya dengan metode online, sistem kerja juga lebih efektif dan efisien dengan pembagian tugas yang baik. Saran kami agar industri ini terus up to dated tentang kemajuan teknologi terutama sistem penjualan saat ini dan terus ber inovasi mengembangkan produknya.
\end{abstract}

Kata Kunci: Penjualan, Wewenang, Tugas, UKM

We carried out Community Service activities in 3 stages: counseling on the development of $e$ commerce sales and the importance of division of tasks, discussions about the obstacles faced, and assistance in making online sales media and preparing organizational structures. After attending the training, the business has progressed rapidly in its sales using the online method. The work system is also more effective and efficient with a good division of tasks. Our advice is to keep this industry up to date on technological advances, especially the current sales system, and continue to innovate to develop their products.

Keywords: Sales, Authority, Duties, SMEs

\section{PENDAHULUAN}

Usaha Kecil adalah usaha yang memiliki tenaga kerja kurang dari 50 orang dan memiliki kekayaan bersih paling banyak Rp200 juta (di luar tanah dan bangunan) berdasarkan UndangUndang Nomor 9 Tahun 1995. Serta, memiliki penjualan paling banyak Rp1 M. Usaha kecil ini harus dimiliki oleh warga negara Indonesia dan berbentuk usaha perorangan, badan usaha, atau koperasi. Usaha kecil umumnya adalah perusahaan perorangan, contohnya restoran lokal, pengusaha konstruksi lokal, laundry, dan toko pakaian lokal. Lalu, ada juga namanya usaha musiman yang artinya usaha tersebut bergantung pada musim tertentu. Usaha Menengah Usaha menengah adalah usaha dalam ekonomi produktif yang berdiri sendiri, dan dilakukan oleh perorangan atau badan usaha yang bukan anak perusahaan atau cabang perusahaan yang dimiliki. Usaha menengah juga bukan dikuasai atau menjadi bagian dengan usaha kecil atau usaha besar. Usaha menengah memiliki jumlah kekayaan bersih sekitar Rp500 jutaRp10 M dan jumlah omzet antara Rp2,5 MRp50 M. Dilihat dari perkembangannya yang signifikan, perkembangan UKM juga sebagai penyumbang pendapatan daerah dan pendapatan negara terbesar. Pada tahun 2007 hingga tahun 2012 saja menunjukkan peningkatan PDB dari RP 2.107.868,10 Milyar menjadi Rp 4.869.568,10 Milyar. Oleh karena itu tak salah jika pemerintah menurunkan pajak UKM agar UKM semakin tumbuh dan berkembang.

Tingginya permintaan masyarakat akan kerupuk ikan membuat UKM ini semakin dikenal. Rasa kerupuk yang berbeda dari tempat lain dengan harga yang lebih murah di kelasnya membuat usaha ini bisa bertahan di tangah pandemi. Dengan demikian ini sangat membantu para pekerja untuk mendapatkan penghasilan lebih 
dengan ditandainya peningkatan produksi. Banyaknya permintaan tidak mengurangi kualitas minuman dan makanan yang dihasilkan. Potensi dan sumber daya alam yang ada di sekitar khususnya anak muda, sangat membantu berkembangnya usaha ini. Pemilihan kualitas bahan-bahan kerupuk sebagai menjadi pertimbangan pemilik untuk bersaing dengan usaha yang sama dari tempat lain .

Dari segi penjualan atau pemasaranpun masih ada yang perlu ditingkatkan. Pemasaran merupakan satu fungsi organisasi dan seperangkat proses untuk menciptakan, mengkomunikasikan, dan menyerahkan nilai kepada pelanggan dan mengelola hubungan pelanggan dengan cara yang menguntungkan organisasi dan para pemilik sahamnya. Sedangkan manajemen adalah proses perencanaan, pengorganisasian, kepemimpinan, dan pengawasan kegiatan anggota serta tujuan penggunaan organisasi yang sudah ditentukan.

Selain itu, dari hasil wawancara kami juga diketahui bahwa UKM " Usaha Krupuk Super Ikan laut, Mandiri" belum memiliki struktur organisasi yang jelas. Struktur organisasi merupakan rancangan dari pemimpin organisasi sehingga mampu menentukan harapan-harapan mengenai apa yang akan dilakukan individu-individu dan kelompok kelompok tersebut dalam mencapai tujuan-tujuan organisasi (Ivancevich, 2007). Oleh karena itu struktur organisasi didesain dengan baik untuk sebuah organisasi yang efektif yang mana dengan adanya sumber daya manusia dalam organisasi perusahaan struktur organisasi dapat diimplementasikan sesuai sistem kerja organisasi untuk tujuan organisasi yang efektif dan efisien. (Gammahendra, 2014)

Berdasarkan hasil observasi dan diskusi bersama mitra, kami menemukan dua poin besar permasalahan yang terjadi di UKM yang akan lakukan penelitian, yaitu dari segi pemasaran, dan manajemen. Pemasaran berbasis teknologi yang tak begitu di kuasai oleh mitra dapat menurunkan omset. Pemasaran menggunakan media sosial dan situs online sangat mempengaruhi omset sebuah UKM. Seseorang yang ditunjuk sebagai admin pemasaran online harus lincah memposting barang yang akan dipasarkan. Selaian itu, seorang admin harus mampu menguasai teknologi digital. Dari segi manajemen, permasalahan yang kami temui adalah belum rapinya struktur organisasi karena banyaknya pemilik sehingga mengganggu perencanaan dan penggunaan sumber dayasumber daya lainnya dalam mencapai tujuan UKM. Dalam manajemen ada proses pendelegasian dan kewenangan. Manajemen yang belum terstruktur membuat kami meberikan solusi untuk merapikan struktur organisasi di UKM ini. Serta membuat job description pekerja agar tak terjadi tumpang tindih pekerjaan. Dengan banyakya owner, harus ada pembagian dan penjadwalan pengecekan yang bergantian.

\section{METODE}

Langkah awal yang kami lakukan adalah dengan survey atau peninjauan lapangan dengan mitra untuk mengetahui permasalahan di lapangan yang sedang mereka hadapi. Pelaksanaan pengabdian kepada masyarakat ini kami selenggarakan secara daring dari tanggal 21 Juni sampai dengan 23 Juni 2021 melalui Zoom.

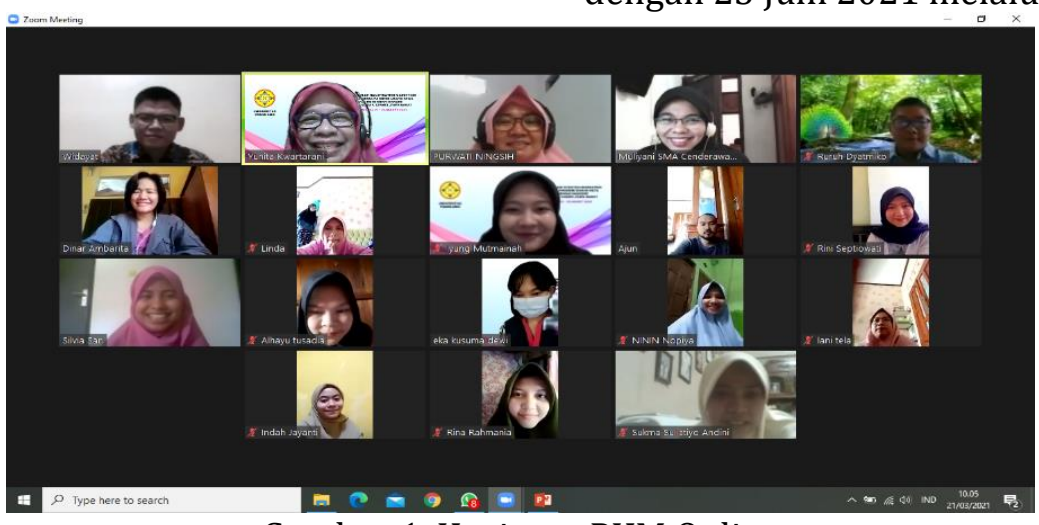

Gambar 1. Kegiatan PKM Online 
Kegiatan pengabdian masayarakat dilakukan dengan pendekatan workshop, meliputi:

1. Penyuluhan, tanya jawab. Penyuluhan digunakan untuk menyampaikan penjelasan kepada peserta tentang materi terkait cara dan manfaat teknik pemasaran penjualan menggunakan fasilitas e-commerce. Pada sesi ini juga disampaikan beberapa contoh sukses penjualan yang menggunakan basis ecommerce yang kebetulan dimiliki oleh salah satu anggota tim pengabdi kami. Selain itu dijelaskan juga tentang pentingnya struktur organisasi, dan pembagian wewenang serta tugas.

2. Diskusi. Diskusi dilakukan untuk menggali persoalan-persoalan yang berhubungan dengan pemasaran dengan menggunakan fasilitas e-commerce dan pembagian wewenang dan tugas di UKM " Usaha Krupuk Super Ikan laut, Mandiri".

3. Pendampingan Pendampingan ini bertujuan memberikan pengarahan pada saat pembuatan E-commerce dan pembagian wewenang dan tugas di UKM " Usaha Krupuk Super Ikan laut, Mandiri".

\section{HASIL DAN PEMBAHASAN}

E-Commerce adalah suatu jenis dari mekanisme bisnis secara elektronik yang memfokuskan diri pada transaksi bisnis berbasis individu dengan menggunakan internet (teknologi berbasis jaringan digital) sebagai medium pertukaran barang atau jasa baik antara dua buah institusi (business to business) dan konsumen langsung (business to consumer).

E-Commerce adalah suatu jenis dari mekanisme bisnis secara elektronik yang memfokuskan diri pada transaksi bisnis berbasis individu dengan menggunakan internet (teknologi berbasis jaringan digital) sebagai medium pertukaran barang atau jasa baik antara dua buah institusi (business to business) dan konsumen langsung (business to consumer).

Dengan perubahan ke arah ekonomi baru dimana para penjual dan pembeli tidak saling bertemu secara langsung maka untuk bertransaksi menggunakan sistem pembayaran non tunai. Metode transaksi yang digunakan pada $e$ commerce berupa less cash, baik itu melalui Anjungan Tunai Mandiri (ATM), Electronic Fund Transfer (EFT), mobile banking, online banking, Electronik Data Interchange (EDI) dan juga untuk melakukan transaksi $e$ commerce dibutuhkan telekomunikasi berupa internet.

Kehadiran e-commerce kini dianggap sebagai bantuan bagi para pelaku Usaha Mikro, Kecil, dan Menengah (UMKM) di Indonesia. Dengan bantuan beragam program inovatif, pelaku UMKM bisa memasarkan barang dagangannya lebih luas lagi, bahkan ke pasar internasional secara efektif dan dengan performa yang maksimal. Jadi tidak berlebihan rasanya jika e-commerce dikatakan sebagai salah satu faktor kebangkitan UMKM Indonesia, sekaligus pertumbuhan ekonomi digital di Indonesia. Faktanya, terdapat beberapa manfaat untuk UMKM di Indonesia dari hadirnya e-commerce, yaitu memudahkan para mereka untuk dapat berkomunikasi dengan calon konsumennya. Komunikasi serta informasi yang jelas dari penjual, akan membuka peluang lebih besar bagi pedagang untuk mendapatkan keuntungan yang lebih besar lagi. (Reza, 2019)

Division of Labor atau Pembagian Tugas adalah konsep ekonomi yang menyatakan bahwa membagi proses produksi ke dalam tahapan yang berbeda yang memungkinkan pekerja fokus pada tugas-tugas tertentu. Jika pekerja dapat berkonsentrasi pada satu aspek kecil dari produksi, ini akan meningkatkan efisiensi keseluruhan. Pembagian tugas paling sering diterapkan pada sistem produksi massal dan merupakan salah satu prinsip pengorganisasian dasar agar proses produksi menjadi lebih cepat. Pembagian tugas menggabungkan spesialisasi dari tugas produksi yang kompleks menjadi banyak atau beberapa. Dengan pembagian tugas kerjaPentingnya dalam ekonomi terletak pada kenyataan bahwa sejumlah pekerja dapat menghasilkan output yang jauh lebih banyak dengan menggunakan pembagian kerja dibandingkan dengan jumlah pekerja yang sama jika masingmasing bekerja sendiri. (Gulla, 2018)

Ada 4 pembagian kerja, yaitu : 
1. Pembagian Tugas yang sederhana

Ini berarti pembagian orang dalam masyarakat menurut pekerjaan. Dalam hal ini setiap individu mengambil jenis pekerjaan tertentu yang paling cocok bagi dirinya. Jadi, di masyarakat ada yang menjadi guru, dokter, pedagang, dan lainnya. Ketika seluruh karya produksi tertentu dilakukan oleh pekerja yang sama, hal ini disebut simple division of labor.

2. Pembagian Tugas menjadi proses lengkap atau pembagian tugas yang kompleks

Ketika seluruh pekerjaan dalam produksi suatu komunitas dibagi menjadi proses yang berbeda dan setiap proses diberikan kepada orang yang berbeda itu disebut "proses spesialiasasi". dibawah dari proses spesialisasi tersedia divisi-divisi tertentu dan setiap divisi atau proses dilakukan oleh satu orang.

3. Pembagian Tugas menjadi sub-proses

Ketika proses lengkap dibagi menjadi sub-proses dan kemudian pekerjaan selesai, ini disebut pembagian tugas sub-proses. Satu proses tidak lengkap tanpa bantuan dan kerjasama proses lainnya, ini juga disebut "personal pembagian tugas".

4. Pembagian Tugas wilayah atau geografis

Ketika suatu tempat atau wilayah khusus industri tertentu atau dalam produksi komoditas tertentu.

\section{PENUTUP}

Dari kegiatan yang kami laksanakan, diketahui beberapa masalah yang dihadapi oleh "Usaha Kerupuk Super Ikan Laut Mandiri" yaitu diantaranya minim nya modal yang mereka miliki, pengelolaan keuangan yang belum baik dengan pembukuan yang sangat sederhana, pemasaran yang bersifat tradisional hanya berada di sekitar Ciamis, kurangnya inovasi, dan tidak ada pembagian tugas dan tanggung jawab yang jelas diantara pemilik dan karyawan. Setelah kami mengadakan kegiatan Pengabdian Kepada Masyarakat, Usaha Kerupuk Super Ikan Laut Mandiri mengalami kemajuan dalam hal strategi penjualan dan pembagian tugas dan tanggung jawab diantara mereka. Mereka sudah melakukan penjualan online melalui e-commerce shopee dan Tokopedia, yang berdampak meningkatnya pesanan produk usaha kerupuk mereka. Pembagian tugas dan tanggung jawab pun sudah ter distribusi dengan baik sesuai dengan kapasitas masing masing pemilik dan karyawan "Usaha Kerupuk Super Ikan Laut Mandiri"

Setelah mengikuti pelatihan yang kami lakukan,Usaha Kerupuk Super Ikan Laut, Mandiri mengalami peningkatan dalam permintaan dan pendapatan. Serta melakukan reformasi dalam berbagai bidang yaitu keuangan, pemasaran, dan produksi.

Adapun saran yang bisa kami berikan, agar "Usaha Kerupuk Super Ikan Laut Mandiri" untuk terus up to dated terhadap perkembangan tehnologi terutama penjualan serta membuka cakrawala untuk terus ber inovasi mengembangkan produknya.

\section{DAFTAR PUSTAKA}

Abdullah,Thamrin., \& Francis Tantri. (2012). Manajemen Pemasaran. Jakarta: Rajawali Pers.

Daryanto. (2011). Sari Kuliah Manajemen Pemasaran. Bandung: Sarana Tutorial Nurani Sejahtera

Erlangga, H, et al. (2019). Pengaruh Kegiatan Promosi Terhadap Keputusan Pembelian Konsumen Pada PT. Modise Busana Sejati Di Bandung. Jurnal Ekonomi Efektif, 1(4).

(2020). Pengembangan Kapasitas Usaha Kecil Kerupuk Kentang Di Kampung Ciawitali Desa Warnasari Kecamatan Pangalengan Kabupaten Bandung. Jurnal Pengabdian Tri Bhakti, 102-109.

Gammahendra, Fianda., \& Djamhur Hamid dan Muhammad Faisal Riza. (2014). Pengaruh Struktur Organisasi terhadap Efektivitas Organisasi (Studi Pada Persepsi Pegawai Tetap Kantor Perwakilan Bank Indonesia Kediri). Jurnal Administrasi Bisnis (JAB). Vol. 7 No. 2 Januari 2014.

Gulla, Thrisya Marcelina. (2018). Divisoin of Labor. (on line). Dari: 
https://www.ukmindonesia.id/bacaartikel/83 (17 Juni 2021)

Hasibuan, Malayu. (2016). Manajemen Sumber Daya Manusia. Jakarta: Penerbit Bumi Aksara.

Ivancevich, John M., Konopaske, Robert., \& Matteson, Michael T. (2007). Perilaku dan Manajemen Organisasi. Jakarta: PENERBIT ERLANGGA

Kotler, Philip., \& Gary Amstrong. (2008). Prinsip-Prinsip Pemasaran (Edisi Keduabelas). Jakarta: Erlangga.

Muhammad Fadli (2020). Analysis of Division Of Labor Ang Authority Employees In Raising Workachievement At CV .Aneka Jaya. Meraja Journal. Vol 3, No. 3, November 2020.

Nurjaya, N., et al. (2021). The Effect of Product Promotion and Innovation Activities on Marketing Performance in Middle Small Micro Enterprises in Cianjur. Budapest International Research and Critics Institute (BIRCIJournal): Humanities and Social Sciences, 4(1), 528-540.

Purwanto, A., et al. (2021). The Role of Brand Image, Food Safety, Awareness, Certification on Halal Food Purchase Intention: An Empirical Study on Indonesian Consumers. Journal of
Industrial Engineering \& Management Research, 2(3), 42-52.

Putra, Fahmi Rachmanda. (2017). Peran ECommerce dalam Pengembangan Usaha Mikro, Kecil dan Menengah (UMKM) untuk Mewujudkan Less Cash Society. (on line) Dari: https://iain-surakarta.ac.id/peran-ecommerce-dalam-pengembanganusaha-mikro-kecil-dan-menengahumkm-untuk-mewujudkan-less-cashsociety/ (17 Juni 2021)

Reza (2019). Peran E-Commerce bagi UMKM di Indonesia. (on line). Dari: https://www.liputan6.com/news/rea d/4128517/peran-e-commerce-bagiumkm-di-indonesia . (17 Juni 2021)

Suwanto, S. (2021). Pengaruh Strategi Promosi Dan Harga Terhadap Keputusan Pembelian Produk Bahan Baku Biji Plastik Pada Pt. Kurnia Makmur Jaya Lestari Di Gading Serpong. Jurnal Ekonomi Efektif, 3(2).

Swastha, Basu. (2009). Manajemen Penjualan (edisi ketiga). Yogyakarta: BPFE.

Wangsi, M. M., \& Rawi, R. D. P. (2018). Perlindungan Konsumen Dalam Pelabelan Produk Menurut Ekonomi Islam. Sentralisasi, 7(1), 1-9. 